\title{
UMA DESCRIÇÃO INICIAL DO PRESENTE PERFEITO NA LIBRAS
}

\author{
PRESENT PERFECT IN BRAZILIAN SIGN \\ LANGUAGE: AN INITIAL DESCRIPTION
}

\author{
ROBERLEI ALVES BERTUCCI ${ }^{1}$ \\ (UTFPR) \\ ROSSANA APARECIDA FINAU ${ }^{2}$ \\ (UTFPR)
}

\begin{abstract}
RESUMO: Este trabalho tem como objetivo principal descrever os modos de expressão, na Libras, do que se denomina, na literatura, de presente perfeito. Considerando que a descrição de tempo e aspecto nessa língua já vem sendo feita há algum tempo, conforme se observa nos trabalhos de Felipe (1998), Finau (2004; 2008) e Silva e Lessa-de-Oliveira (2016), no presente artigo pretendemos analisar um caso mais específico de composição tempo-aspectual, verificando de que forma diferentes leituras semânticas, relacionadas ao presente perfeito, conforme a descrição de Laca (2010), podem ser expressas na Libras. Para o trabalho, analisamos sentenças produzidas por Surdos, cujos dados revelam que as diferentes leituras do presente perfeito são dadas por basicamente duas formas, o presente e o passado, condicionadas por diferentes fatores na composição da sentença, em especial o aspecto lexical e o contexto do momento de tópico.
\end{abstract}

PALAVRAS-CHAVE: Libras; tempo verbal; presente perfeito.

ABSTRACT: This work aims to describe some present perfect readings in Brazilian Sign Language (Libras). In the last years, research has been made on tense and aspect in this language, as one can observe in Felipe (1998), Finau (2004; 2008) and Silva e Lessa-de-Oliveira (2016). In the present paper, we adopt Laca's (2010) descriptions of present perfect readings and we investigate how some of them can be expressed in Libras. In this paper we analyze some sentences produced in Libras, whose results show that different present perfect readings are expressed basically by simple present and simple past tenses, and they are especially related to lexical aspect and contextual reference to topic time.

KEYWORDS: Brazilian Sign Language; tense; present perfect.

\footnotetext{
${ }^{1}$ bertucci@utfpr.edu.br

2 rossana@utfpr.edu.br
} 


\section{INTRODUÇ̃̃O}

O tempo é, sem dúvida, uma categoria essencial para as possibilidades de expressão em língua natural. Assim, entender como se expressam as categorias de tempo e aspecto é importante para as pesquisas linguísticas. Neste trabalho, nossa proposta é avaliar de que modo a noção de presente perfeito-mais especificamente, suas leituras - é expresso na Libras. Partiremos da proposta de Laca (2010), para quem as diferentes leituras do presente perfeito se relacionam com a composição dos elementos no contexto e na sentença. Considerando as pesquisas na área de tempo e aspecto que têm sido feitas sobre a Libras, tal como se pode observar nos trabalhos de Felipe (1998), Finau (2004; 2008) e Silva e Lessa-de-Oliveira (2016), entre outros, assumiremos que as noções de tempo e aspecto estão bem descritas, o que nos permite focar neste tempo verbal mais específico: o presente perfeito. Vamos assumir, para este trabalho, que o presente perfeito seja um tempo verbal (no sentido de tense, em inglês) com leituras específicas. No PB e na Libras, no entanto, veremos que ele não se manifesta como um tempo verbal, mas suas leituras são expressas por estruturas gramaticais relativamente distintas daquelas do inglês e do espanhol.

Dessa forma, perseguiremos duas questões principais: como a Libras expressa algumas noções básicas de presente perfeito, conforme as leituras analisadas por Laca (2010)? Quais seriam as semelhanças e diferenças básicas de expressão do presente perfeito entre o português brasileiro (PB) e a Libras? Por questões de espaço, nosso enfoque será sobre as leituras universal, existencial, de novidade (ou hot news) e resultativa, explicadas adiante.

De antemão, vale considerar que a noção aspectual do presente perfeito é desencadeada por estruturas distintas em diferentes línguas: enquanto em línguas como inglês o auxiliar have é comumente associado ao presente perfeito (1a), o auxiliar ter aparece sob condições específicas em português, mais precisamente, em contextos de iteração, como se vê em (1b). Esse tempo verbal também pode ser expresso por verbos simples no passado ou no presente no PB (1c). ${ }^{3}$

(1) a. Mary has lived in Curitiba.

b. Maria tem morado em Curitiba.

c. Maria morou/mora em Curitiba.

Outro ponto importante é a relação do presente perfeito com modificadores adverbiais. Se levarmos em conta as diferentes leituras desse tempo verbal, tal como nos apontam Portner (2003), Mittwoch (2008) e Laca (2010), alguns modificadores adverbiais parecem ser a chave para definir uma leitura contínua (2) ou uma leitura de experiência (3), por exemplo.

${ }^{3}$ Lopes (2016) faz uma importante comparação entre os modos de expressão das leituras universal e existencial entre o português brasileiro (PB) e o inglês britânico (IB), especialmente quanto à composição sintática. Agradecemos a um dos pareceristas pela indicação dessa referência. 
(2) a. Mary has lived in Curitiba since 2010.

b. Maria mora em Curitiba desde 2010 .

(3) a. Mary has lived in Curitiba once.

b. Maria morou em Curitiba uma vez.

Vemos que, se em inglês a estrutura do presente perfeito pode ser a mesma para as duas leituras $(2 \mathrm{a} / 3 \mathrm{a})$, sendo a diferença básica delas disparada pelos modificadores em cada sentença, no PB a própria morfologia verbal é diferente: a leitura universal (2b) aparece no presente do indicativo (imperfectivo), e a leitura existencial (3b), no pretérito perfeito (perfectivo).

Não menos importantes serão as características aspectuais dos predicados envolvidos nas sentenças, especialmente no que diz respeito às classes verbais (VENDLER 1957). Nesse caso, algumas leituras serão licenciadas apenas quando a sentença for constituída de classes específicas, como a chamada leitura de novidade (ou "hot-news", em Laca, 2010), que parece ser adequada apenas em contexto de telicidade (4).

(4) a. The cat has run away!

b. O gato fugiu!

No presente trabalho, trataremos, basicamente, da relação entre as classes aspectuais (aspecto lexical) e do aspecto gramatical (perfectivo/imperfectivo) para a expressão do presente perfeito. De algum modo, ele contribui para uma discussão importante sobre a forma como os tipos de aspecto são expressos translinguisticamente (ROTHSTEIN 2008).

$\mathrm{O}$ artigo se organiza desta maneira: na primeira parte, trataremos das noções de tempo e aspecto assumidas neste trabalho; na segunda parte, do aspecto lexical; em seguida, mostraremos as características do presente perfeito, especialmente no que diz respeito às diferentes leituras que ele denota, incluindo o papel da perífrase ter+particípio no PB; na quarta parte, apresentaremos as noções de tempo e aspecto na Libras; e, na seção 5, analisaremos os dados para, em seguida, apresentarmos as considerações finais.

\section{TEMPO E ASPECTO COMO CATEGORIAS DÊITICAS}

Em seus trabalhos, Klein $(1994 ; 2009)$ afirma que é possível propor definições para tempo e aspecto mais precisas do que as encontradas na literatura, consideradas por ele incompletas ou metafóricas. Assim, de um lado, o autor propõe que a noção reichenbachniana de relação entre momentos de tempo seja aprofundada, já que Reichenbach (1947), entre outras coisas, não define o que chama de "momento de referência", nem leva em conta a propriedade dos 
predicados para a expressão temporal nas línguas naturais. De outro lado, Klein (1994) propõe que a noção de aspecto também seja dada a partir de relações entre intervalos temporais e não metaforicamente, como se vê na tradição - a proposta de Comrie (1976, p. 3), por exemplo, é uma das mais empregadas para tratar do tema, definindo aspecto como "diferentes maneiras de visualizar a constituição temporal interna" de uma situação. Klein (1994; 2009) acredita, assim, haver uma maior possibilidade de explicação para as formas de expressão nas línguas naturais das experiências humanas sobre o tempo. ${ }^{4}$

Neste trabalho, vamos assumir a noção de Klein (1994) de que tanto tempo quanto aspecto são categorias dêiticas, num desdobramento da discussão realizada em Reichenbach (1947). Klein (1994, p. 3) sugere que

tempo pode ser definido em termos de relações temporais, como antes, depois e simultâneo, e aspecto, em termos de anterioridade, inclusão ou posterioridade, por exemplo. A maior diferença entre tempo e aspecto seria em relação a que momento estão relacionados.

Para Klein (1994), tempo e aspecto devem ser pensados a partir de três momentos distintos: o momento de tópico (TT), que é o momento sobre o qual o falante faz a asserção; o momento de fala (TU), o momento em que o falante pronuncia a sentença, e o momento da situação (TSit), relacionado ao evento descrito na sentença. ${ }^{5}$

Nesse sentido, o tempo verbal é determinado pela relação entre TT e TU, de modo que, um evento é descrito: no passado se TT for anterior a TU (5a); no presente, se forem simultâneos (5b); e no futuro, se TT suceder TU (5c). Em (5), o TT é dado pelo evento de chegada do falante (quando eu cheg-).

(5) a. Quando eu cheguei, a porta estava aberta.

b. Quando eu chego, a porta está aberta.

c. Quando eu chegar, a porta estará aberta.

Seguindo as relações entre intervalos de tempo, o aspecto gramatical é determinado pela relação entre TT e TSit; sendo assim, um evento é descrito: no

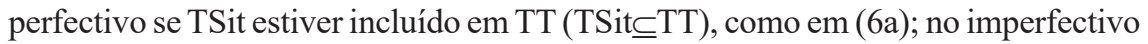
se TT estiver incluído no TSit (TT $\subseteq$ TSit), como em (6b).

(6) a. Ontem na festa, João dançou.

b. Quando a Maria chegou na festa, João estava dançando.

${ }^{4}$ É preciso entender tempo de duas maneiras distintas: primeiro, como algo próprio de nossas experiências (em inglês, a palavra adequada seria time); depois, como algo linguisticamente marcado (em inglês, a palavra adequada seria tense). Como não há equivalência no PB para essa diferenciação, esperamos a compreensão do leitor para acomodar essas noções contextualmente. Agradecemos a um parecerista anônimo que nos induziu a evidenciar essa diferença.

${ }^{5}$ TT é o equivalente a Time of Topic, TU, a Time of Utterance e TSit, a Time of the Situation, em inglês. 
Vemos que em (6a) o evento de João dançar dura um intervalo (TSit) menor que o da festa, o TT. Por outro lado, em (6b), o intervalo que dura o evento de João dançar (TSit) é maior que o da chegada de Maria na festa (TT). Essa descrição para os intervalos de tempo teve sua origem exatamente nos trabalhos de Reinchenbach (1947), os quais pretendiam oferecer uma proposta para análise do presente perfeito, um tempo composto que precisa levar em conta questões de tempo e aspecto. Para o autor, o presente perfeito envolveria questões complexas: sua interpretação/representação deveria levar em conta aspectos de passado (começa ou ocorre num momento anterior ao momento de fala) e de presente (o evento ou seu resultado alcança o momento de fala). Klein (1994; 2009), por sua vez, propõe que a teoria de Reichenbach seja aprofundada, levando em conta o modo como se expressam os três momentos em análise e o aspecto lexical dos predicados envolvidos na composição da sentença. Com isso, se na seção 3, trataremos mais especificamente do presente perfeito, na seção a seguir vamos discutir as noções de aspecto lexical, as quais se constituem um ingrediente importante para a análise geral sobre tempo e aspecto, consequentemente, para o presente perfeito.

\section{ASPECTO LEXICAL}

Na literatura sobre o tema, costumamos encontrar uma diferença importante entre dois tipos de aspecto: o aspecto gramatical, cuja característica básica é apresentar leituras de temporalidade relativas ao evento considerando o momento de tópico, por meio de uma morfologia ou sintaxe específica, como vimos na seção anterior, e o aspecto lexical, cuja característica básica é denotar gradação temporal relativa à forma como as línguas expressam os eventos no mundo no léxico ou em sintagmas, mas sem haver, necessariamente, morfologia e sintaxe específicas. Vamos nos concentrar neste último tipo de aspecto.

Smith (1997) defende que o aspecto lexical esteja relacionado aos "tipos de situações", também conhecidas por Aktionsart. Esses tipos de situações poderiam ser expressos linguisticamente a partir da proposta das quatro classes de verbos de Vendler (1957; 1967): estados, atividades, accomplishments e achievements. Para autores como Smith (1997) e Wachowicz e Foltran (2006), o aspecto lexical é dado pelo verbo, seus complementos e outros elementos que estejam envolvidos na composição do predicado, ou seja, pelo sintagma verbal (VP). Neste trabalho, ressaltamos que as classes vendlerianas (aspecto lexical) formam uma classe aspectual importante para a análise sobre tempo e aspecto (Rothstein 2004; Wachowicz e Foltran 2006; Wachowicz 2008), mais especificamente, para a leitura composicional do presente perfeito.

Rothstein (2004) propõe que as quatro classes de Vendler (estados, achievements, atividades e accomplishments) sejam divididas de acordo com duas propriedades básicas: telicidade e estágios ( \pm télico; \pm estágios). Vamos assumir que telicidade seja dada pela presença clara de um ponto final em um evento denotado por uma expressão linguística. Em geral, esse ponto final é também associado a uma mudança de estado. Essa propriedade diferenciaria eventos como chegar e morar: enquanto o primeiro tem uma mudança de estado clara, ou seja, (+télico), o segundo pode durar indefinidamente, (- télico). 
Para complementar, Rothstein (2004) assume que "ter estágios" é a segunda propriedade capaz de explicar a diferença entre as classes de Vendler. Nós podemos entender essa propriedade assim: um evento possui estágios se ele é composto de diferentes subeventos que ocorrem em momentos diferentes. Atividades, como denotadas por correr, possuem subeventos de corrida (os passos rápidos, por exemplo), que, juntos, formam o evento maior de correr. Se forem interrompidos, não há mais corrida. Por outro lado, estar deitado não possui subeventos menores de estar deitado. Não há nada que possamos interromper e o estado acabar. Vamos resumir essa análise no quadro a seguir.

\begin{tabular}{|l|c|c|l|}
\hline \multicolumn{4}{|c|}{ Quadro 1: Classes de Vendler - aspecto lexical } \\
\hline Classe & \pm estágios & \pm télico & Exemplos \\
\hline EstADOS & - & - & ser alto, estar deitado \\
\hline ACHIEVEMENTS & - & + & chegar, vender a casa \\
\hline ATIVIDADES & + & - & correr, nadar \\
\hline ACCOMPLISHMENTS & + & + & ler o livro, escrever um soneto \\
\hline
\end{tabular}

Como veremos na seção a seguir, as leituras do presente perfeito parecem levar em conta as características do aspecto lexical do evento denotado pelo predicado.

\section{CARACTERÍSTICAS DO PRESENTE PERFEITO}

O presente perfeito em línguas como espanhol e inglês é composto pela combinação de um verbo auxiliar - have, em inglês, e haber, em espanhol - e um verbo no particípio, expressando ações que ocorreram/começaram em algum momento do passado, mas que possuem algum vínculo ou efeito no presente. Como todo tempo verbal, o presente perfeito tem restrições de ocorrência e contexto, como já demonstraram Portner (2003), Mittwoch (2008), Laca (2010), entre outros. Esta última, por exemplo, apresenta pelo menos oito leituras distintas para o presente perfeito em inglês e espanhol; todavia, nosso foco será em quatro delas: universal, existencial, novidade (hot news) e resultativa. Com o intuito de tornar mais concreta a comparação entre Libras e PB, nossos exemplos serão dados todos já nesta última língua, e não em inglês ou espanhol, como se vê na literatura citada acima. No entanto, reforçamos que, nessas línguas, as construções-padrão do presente perfeito são feitas sempre com o auxiliar e um verbo no particípio (ainda que haja ressalvas, como Lopes, 2016).

A leitura universal ocorre quando o fato descrito pelo predicado tem seu início no passado e dura até o momento de fala (7). Nesse caso, trata-se de algo que permanece e que não ficou apenas como uma experiência vivida no passado. 
(7) a. Maria mora em Curitiba desde 2010.

b. Maria tem chegado atrasada ultimamente.

Nos casos em (7), a inserção de desde 2010 ou ultimamente caracteriza a permanência da situação de um ponto no passado até o momento de fala. No que concerne ao aspecto lexical, dada a leitura composicional, os eventos aqui são atélicos, já que precisam ser estendidos no tempo. Do ponto de vista do aspecto gramatical e do tempo, as sentenças com o verbo no presente são essenciais para a leitura universal; já o uso da perífrase com ultimamente (7b) é importante para caracterizar, além da universalidade, a repetição do evento. Nesse sentido, parece claro que a perífrase com ter é um exemplar da leitura de presente perfeito no PB, mas apenas para contextos de repetição, tal como já observaram autores como Schmitt (2000), Ilari (2001), Wachowicz (2006), Molsing (2007), Laca (2010), Medeiros (2010), entre outros.

A leitura existencial acontece quando a sentença apresenta um evento que ocorreu num período indeterminado (8), além de contar como uma experiência, sendo, por isso, também chamada de leitura de experiência. Aqui, diferentemente da leitura universal, não se trata de um estado que permanece, mas sim de algo que ficou no passado.

(8) a. Maria ganhou um prêmio uma vez.

b. Maria já morou em Curitiba.

Nos exemplos acima, os eventos são descritos como uma experiência e inserimos as expressões uma vez e já para destacar essa leitura. Do ponto de vista da Aktionsart, os verbos aqui podem ser télicos (ganhar um prêmio) ou atélicos (morar), desde que restritos a um momento no passado. E, exatamente por isso, diferentemente da leitura universal, aqui é obrigatório que o verbo apareça no pretérito perfeito (passado simples) e sem o uso da perífrase. ${ }^{6}$

A leitura de novidade (ou "hot-news") ocorre quando a sentença apresenta um evento cuja culminação é recente; logo, o estado resultante permanece no momento de fala.

(9) a. O gato acabou de fugir!

b. O gato fugiu!

${ }^{6}$ Vale a pena acrescentar que Lopes (2016) verificou também o uso da perífrase com progressivo tanto no PB quanto no inglês britânico, para a expressão dessa leitura universal. Para a leitura existencial, além do pretérito perfeito no $\mathrm{PB}$, a autora verificou a ocorrência do passado simples em inglês. 
Assim, (9) deve ser utilizada no contexto em que o gato fugiu e, no momento de pronunciamento, o falante tem evidências de que ele ainda não foi encontrado. Aspectualmente, o evento precisa ser télico, já que a leitura é de culminação recente e, para estabelecer essa culminância, a construção no PB é dada pelo verbo no passado simples. ${ }^{7}$

Finalmente, a leitura resultativa ocorre quando o evento descrito pelo presente perfeito apresenta um estado resultante que serve de causa/explicação para uma situação.

(10) Maria não pode tocar, já que ela machucou o braço.

Em (10), a situação de Maria não poder tocar tem como explicação o fato de ela ter machucado o braço. $\mathrm{O}$ aspecto lexical aqui tem relação direta com eventos de mudança de estado (télico), ou seja, aqueles que denotam um estado resultante. Em (10), o estado resultante (estar com o braço machucado) é acarretado pela relação direta de culminância, indicada pelo aspecto perfectivo do verbo no passado (machucou). Do ponto de vista semântico, no entanto, as leituras de novidade e resultativa tratam de algo em comum: o fato de o estado resultante da culminação ser o ponto principal da descrição do evento. Em outras palavras, em $O$ gato fugiu, o foco é o fato de ele ainda não ter sido encontrado, ou estar no estado de "fugido"; em Maria machucou o braço, o foco é o fato de ela ainda estar "machucada" e, no caso da sentença em questão, não poder tocar. Sendo assim, vamos tomar essas leituras como disparadas sob as mesmas condições básicas.

$\mathrm{O}$ quadro a seguir resume as características de leitura do presente perfeito no PB. É importante frisar que, nessa língua, o auxiliar ter só ocorre na leitura universal, diferentemente do inglês e do espanhol, em que sua presença é obrigatória, conforme nos aponta Laca (2010).

\begin{tabular}{|c|c|c|c|}
\hline Leitura & Tempo & Aspecto lexical & Perífrase \\
\cline { 1 - 3 } Universal & Presente & Atélicos & Sim (só para enfatizar a repetição) \\
\cline { 1 - 2 } Existencial & Pretérito & Sem especificação & Não \\
\cline { 1 - 2 } Novidade & \multirow{2}{*}{ Pretérito } & Télicos & Não \\
\cline { 1 - 2 } Resultativa & & & \\
\hline
\end{tabular}

Quadro 2: Resumo das características do presente perfeito no PB

Feitas as considerações gerais sobre tempo, aspecto e presente perfeito, é hora de passarmos à apresentação das questões sobre a Libras. Começamos pelas noções de tempo e aspecto.

${ }^{7}$ Uma possibilidade para expressão desse tipo de leitura no PB é o uso da perífrase acabar de+infinitivo, como em $O$ gato acabou de fugir, em que não teríamos nenhuma dúvida de que o estado de "fugitivo" do gato permanece no momento de fala. No entanto, vamos deixar a discussão de perífrases em aberto, por não ser o foco desta pesquisa. 


\section{TEMPO E ASPECTO NA LIBRAS}

Em seus trabalhos, Finau $(2004 ; 2008)$ amplia as considerações de Felipe (1998), para quem as marcas de tempo na Libras ocorrem por modificação adverbial ou movimentos específicos nos sinais. No presente trabalho, a descrição sobre o sistema temporal e aspectual da Libras parte das propostas de Finau $(2004 ; 2008)$, nas quais se observa que a leitura da temporalidade e aspectualidade, em uma perspectiva semântico-pragmática, é essencialmente composicional nessa língua. Isso porque, conforme a pesquisadora, na Libras, para a denotação de tempo e aspecto entram em jogo propriedades semânticas dos verbos (aspecto lexical) e sua composição com o aspecto gramatical, nas relações entre os momentos de fala, situação e tópico.

Além disso, reforçando o caráter composicional da Libras, a autora salienta que a temporalidade, nessa língua, além de ser dada por operadores específicos pelos sinais HOJE/ PRESENTE, PASSADO e FUTURO - que marcam as relações entre TT e TU -, pode ser denotada, também, por restrições ou alterações no aspecto lexical e/ou gramatical em sua relação com TT. Ainda, a composicionalidade pode ser atestada quando os valores temporais e aspectuais são alterados por flexões (tanto nos operadores temporais quanto nos verbos) e quando tais valores são modificados por expressões adverbiais, por exemplo, sinais IDADE, DEPOIS, ANTES, SEMANA, DIA, ANOS, HORAS, AMANHÃ, ONTEM, ${ }^{8}$ entre outros, como em (11-13):

(11) QUATROANOS FICAR TREINAR LÁ. (RO, E.avi) ${ }^{9}$

"Por quatro anos treinei lá."

Neg

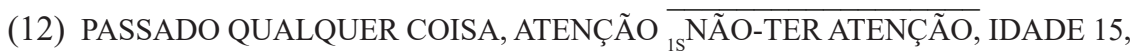
BOB@, BOB@. (RO, E.avi)

"No passado qualquer coisa, não tinha atenção, aos 15 anos, era muito boba."

(13) $\overline{\text { UUNTO+++PRENDER }}$ (Duplicação) +++ DEPOIS++ HABITUAR 19 IDADE ATÉ-ACABAR (JO, A.avi)

"Sempre juntos aprendendo, logo depois, aos dezenove anos, habituei (acostumei)."

\footnotetext{
${ }^{8}$ A transcrição por glosas, neste trabalho, segue Finau (2004) com alterações das propostas de Felipe (1988) e Ferreira-Brito e Langevin (1995) usando a sobrescrição de sinais com __ I para denotar expressão facial de intensidade, _ QU para marcar escopo da expressão facial para pergunta e _ Neg para negação. Ainda, o símbolo + para indicar reduplicação, por exemplo, sinal com morfema reduplicado 2 vezes ++ , três vezes +++ . Justamente por ter valor de destaque para os estudos aspectuais da Libras, conforme Finau (2004), a realização do parâmetro número de mãos (em sinais normalmente feitos com uma) será descrita na glosa pelo termo entre parênteses (Duplicação).

${ }^{9}$ As siglas como (JO, A.avi), que acompanham um grupo de glosas neste artigo, são indicações de dados apresentados por Finau (2004) e, aqui, retomados para análise.
} 
Nas sentenças (11)e(12), o aspecto lexical dos eventos se combina com a restrição temporal dada pelo operador PASSADO, em (12), e por expressões adverbiais: QUATRO ANOS, IDADE 15, em (11) e (12), respectivamente. Em (13), os sinais JUNTO, APRENDER foram realizados com flexão. O primeiro por reduplicação, produzindo a leitura derivada para "sempre juntos". Já o verbo APRENDER, além de reduplicação, sofreu alteração dos parâmetros número de mão e direção, pois foi empregado com duplicação simétrica e realizado com movimentos repetidos circulares, além de alongamento. Essas flexões alteram a leitura da telicidade desse verbo 'aprender' para uma possível aspectualidade gramatical de imperfectivo, pois é pouco provável que todas essas alterações de parâmetros ocorressem sem objetivar uma significação distinta daquela que poderia ser dada pela simples ocorrência do verbo sem flexão a fim de denotar telicidade e, assim, leitura de passado. Nesse sentido, cabe aqui esclarecer que, para Finau (2004), no processo composicional da Libras, sem marcações adicionais na sentença, verbos télicos selecionam leituras compatíveis com o aspecto perfectivo, enquanto os atélicos, com o imperfectivo. Já o emprego de operadores temporais, flexão, advérbios e complementos verbais podem provocar mudanças tanto para leituras de aspecto lexical quanto gramatical.

Finau $(2004,2008)$ ainda observa em sua descrição que a composicionalidade para expressar tempo e aspecto, na Libras, também prevê a necessidade de conhecimento pragmático compartilhado entre os falantes, seguindo, entre outros, Levinson (2000), ao propor que leituras temporais podem ser dadas pragmaticamente por meio de informações colocadas, indiretamente, na estrutura linguística e, assim, presumidas por default - Klein $(1994 ; 2009)$ comenta sobre essa possibilidade nas línguas naturais. Assim, na Libras, o futuro tem uma estrutura estereotipada, exigindo um operador temporal FUTURO; o passado pode ocorrer com operador PASSADO e expressões adverbiais que provoquem leitura perfectiva ou ser dado pela telicidade dos verbos; o presente é dado por default, justamente pela ausência de marcas para passado ou futuro, ou seja, por contraste significativo. O presente também apresenta o sinal HOJE, que pode vir a ser estudado como operador do tempo presente, mas, de acordo com a autora, raramente é empregado nesse sentido, pois seria mais usado como advérbio de intensificação ou marcador discursivo. Exemplos de Finau (2004) para essas situações, entre outros, são:

(14) MARCA TER CADA MARCA (AM, D.avi) $)^{10}$

"Cada um tem uma marca."

(15) CASA CHEGAR MENINO (JO, A.avi)

"O menino chegou em casa."

(16) DEPOIS ESTUDAR. (FR, A.avi)

"Depois estudarei."

(17) FUTURO ESTUDAR FACULDADE MATEMÁTICA. (FR, A.avi)

"No futuro estudarei faculdade de matemática."

${ }^{10} \mathrm{O}$ sinal CADA foi realizado em $\mathrm{D}$, palma para dentro, em semi-círculo, incorporando a representação de PESSOA. 
Em (14), a ausência de operador de FUTURO ou PASSADO, bem como a atelicidade do predicado ter uma marca, orienta para uma leitura de tempo presente. Em (15), apesar da mesma ausência de operadores, a telicidade do verbo seleciona o tempo passado. Já em (16) e (17), são empregados os operadores DEPOIS e FUTURO. Se tais operadores podem ser tomados como relacionados ao momento de tópico ou de situação, é possível analisá-los tanto como operadores temporais quanto aspectuais, conforme a autora, mostrando a relação composicional que há entre tempo e aspecto nas sentenças da Libras, e conforme as bases teóricas sobre as quais estabelecemos esta pesquisa.

Desse modo, reapresenta-se aqui a síntese da autora em termos, agora, das relações temporais e aspectuais propostas por Klein (1994):

a) Atelicidade e imperfectividade selecionam, por default, leitura para tempo presente, a não ser que tenha a situação delimitada por um operador temporal ou por um advérbio, o qual determina que TSitÍTT ou TT $<$ TU.

b) Telicidade e perfectividade selecionam, por default, tempo passado, a menos que seja denotado por operador temporal ou por um advérbio um intervalo de tempo em que TU£TT.

\begin{tabular}{|c|c|c|c|}
\hline Tempo & Aspecto Lexical & Aspecto gramatical & Operador/Advérbio \\
\hline Presente & Atélico & Imperfectivo & Não necessário \\
\hline Passado & Télico & Perfectivo & $\begin{array}{c}\text { Necessário para atelicidade } \\
\text { e imperfectividade }\end{array}$ \\
\hline Futuro & Ambos & Ambos & Necessário \\
\hline
\end{tabular}

Quadro 3: Relação entre tempo, aspecto lexical e aspecto gramatical na Libras

Com todos os ingredientes envolvendo nossa proposta de trabalho já colocados, podemos levantar algumas hipóteses com relação ao modo como a Libras apresentaria as leituras de presente perfeito que são foco de nossa descrição. Dadas as relações de composição exigidas por essa língua, podemos esperar que: i) a leitura universal seja realizada com verbos atélicos e no tempo presente (default); no caso de repetição, deve-se inserir algum tipo de operador na sentença que possa indicar a iteração; ii) a leitura existencial poderá ser feita, de um lado, com verbos télicos, sem marcação temporal explícita (graças ao aspecto lexical do verbo), nem marcação de evento único obrigatórios, de outro, com verbos atélicos, mas, nesse caso, a marcação de passado seria obrigatória, já que seu aspecto lexical poderia levar a uma leitura de continuidade (ou de presente); iii) as leituras de novidade e resultativa ocorreriam apenas com verbos télicos, sem marcação temporal explícita, mas podendo requisitar informações contextuais para serem especificadas. Passemos para a seção de análise dos dados, a fim de verificar se eles corroboram ou refutam as hipóteses aqui levantadas. 


\section{ANÁLISE DOS DADOS}

Para a análise aqui realizada, a coletada de dados se deu em três formatos. Isso porque, dado o caráter inicial da pesquisa, a melhor forma para se realizar tal coleta ainda está em estudo. Assim, alguns dados são aproveitados de trabalhos já realizados sobre aspecto como os de Finau (2004) e Silva e Lessa-de-Oliveira (2016), pois deram subsídios para as hipóteses aqui investigadas. Os dados de Finau (2004), como já explicado, são aqueles apresentados seguidos de códigos para busca de filmagens como (AB, E.avi) e os de Lessa-de-Oliveira (2016) serão indicados junto das sentenças.

Além desses dados, outras duas estratégias foram usadas para a coleta de mais exemplares de enunciados. Em ambas, o mesmo informante surdo, adulto, com grau de escolarização em nível de especialização, usuário da Libras desde a infância produziu as sentenças. Também para as duas estratégias, os dados foram captados em vídeos e transcritos em glosas com ajuda de intérpretes neste momento. ${ }^{11}$

O emprego das duas estratégias para complementar o corpus foi motivado pela preocupação com o fato de que, para análise dos fenômenos temporais e aspectuais, é preciso considerar o funcionamento de línguas, as quais, em contextos similares, podem ou não apresentar contrastes aspectuais explícitos e solicitar somente a tradução de uma língua para outra pode gerar espelhamento. Por isso, a primeira estratégia foi a de apresentar sentenças em português escrito, com leituras específicas do presente perfeito, para serem produzidas na Libras, mas, justamente, para checagem e comparação dos recursos empregados pelo informante, a segunda estratégia foi a de apresentar, por escrito, contextos que provocavam a necessidade de produzir sentenças para descrever eventos com leitura de presente perfeito - essas para uma tentativa de evitar o espelhamento com a língua portuguesa. Ressalta-se que, para ambas as estratégias de coleta, houve apoio de intérprete, apenas, explicando os procedimentos ao informante, mas em nenhum momento traduzindo as sentenças ou os contextos dados, uma vez que o informante tem domínio da escrita / leitura em português. Para a apresentação dessas produções, os exemplares da primeira estratégia são marcados como (Tradução.avi) e os da segunda como (Contexto.avi). Segue a apresentação dos dados a partir das hipóteses apresentadas. ${ }^{12}$

Para a leitura universal, nossa expectativa era de que fosse realizada com verbos atélicos e no tempo presente (default); no caso de repetição, seria necessário inserir algum operador na sentença que indicasse a iteração. Os dados em (18-19) confirmam essa hipótese.

\footnotetext{
${ }^{11}$ Infelizmente, para este artigo, não é possível apresentar as imagens, por conta do espaço. Também por isso serão evitadas descrições mais detalhadas sobre os sinais, destacando-se apenas aquelas necessárias para compreensão da análise sobre o presente perfeito.

${ }^{12}$ Alguém poderia questionar o fato de que o informante pode não ter entendido o contexto ou a formulação do teste para produzir e compreender as sentenças aqui pesquisadas, sugerindo que se fizesse um teste de compreensão com outros Surdos. De fato, isso é o que pretendemos realizar na sequência; por isso, consideramos que, no presente artigo, oferecemos apenas uma "descrição inicial" do presente perfeito na Libras.
} 
(18) J-O-Ã-O MOR[ar] AQUI (Silva e Lessa-de-Oliveira, 2016, ex. 4b) 'João mora aqui'

A sentença em (18) mostra o caso de leitura universal sem repetição, já que a sentença pode denotar a noção de presente (João mora aqui) ou de presente perfeito (João mora aqui desde...). Com repetição, a situação muda, como se vê em (19).

(19) a. PESSOA J-O-Ã-O CHEGAR DEPOIS SEMPRE ${ }^{++(\text {(Duplicąão) }}$ (Tradução.avi) 'João tem chegado atrasado'

b. JOÃO SISTEMÁTIC@ CHEGAR DEPOIS. 'João tem chegado atrasado'

(Tradução.avi)

Por outro lado, a leitura universal com repetição exige algum tipo de operação na sentença: com o evento de João chegar atrasado, foram sinalizadas as sentenças em (19a), com a repetição de sempre, e (19b), com o advérbio sistematicamente. Ressalta-se que (19a) também poderia ter a leitura de João sempre chega atrasado (presente simples). Logo, é o contexto que deverá fornecer o momento de tópico adequado para uma ou outra interpretação.

A noção de permanência na leitura universal do presente perfeito fica também evidenciada em (20), a seguir, em que o falante utiliza a noção de presente contínuo para descrever um estado que permanece de um ponto anterior (domingo) até o momento de fala.

\section{(20) EU ESTUDAR FOCO PROVA. VAI DOMINGO PROVA EU FOCO ESTUDAR.}

'Tenho estudado para a prova desde domingo'

A produção de (20) se deu a partir da solicitação da tradução da sentença "Tenho estudado para a prova desde domingo", e chamou a atenção o uso do sinal VAI, que, nesse caso, também por conta de marcas não manuais com expressão facial e corporal (bochechas infladas associada a sopro, mais cabeça inclinada para o lado), foi entendido mais como denotando que o evento de estudar se deu por todo o dia de domingo e seguiu assim com o foco em estudar, assim a duração temporal com VAI DOMINGO (desde domingo) estaria explicitada. ${ }^{14}$ Veja-se que, para marcar a continuidade, houve a sinalização repetida de estudar, foco, prova. Todos esses casos comprovam que a leitura universal requer eventos que permitem leitura atélica (estudar, morar ou chegar atrasado). Para a repetição/continuidade, embora diversas, houve estratégias de sinalização para que a iteração ficasse clara.

${ }^{13}$ Para a transcrição de Libras, as autoras utilizam o SEL (sistema de escrita para línguas de sinais). Sugere-se o acesso em "Escrita SEL", disponível em <www.sel-libras.blogspot.com.br> Acesso em: 16. jun. 2017.

${ }^{14}$ Esse uso do VAI chamou a atenção dos pesquisadores que estão mais habituados com seu emprego como um possível operador de FUTURO, em algumas regiões do país, porém, nessa ocorrência, o informante, ao se valer de processos não manuais, parece ter modificado o sentido do verbo, gerando uma leitura de duração temporal. Uma alternativa para a glosa em (20) seria o uso de IR no lugar de VAI. 
Com relação à leitura existencial, esperávamos que fosse realizada de dois modos: primeiro, com verbos télicos, sem marcação temporal explícita (graças ao aspecto lexical do verbo), nem marcação de evento único obrigatórios; depois, com verbos atélicos, mas com marcação de passado obrigatória, já que sua atelicidade poderia levar a uma leitura de continuidade. Os dados em (21-22) confirmam nossas hipóteses.

(21) MUIT[as] PESSOA[s] MORR[er] AQUI (Silva e Lessa-de-Oliveira, 2016, ex. 10b) 'Muitas pessoas morrem/morreram aqui'

(22) PASSADO EU MOR[ar] AQUI

(Silva e Lessa-de-Oliveira, 2016, ex. 8b)

'Eu morava/morei aqui.'

A sentença em (21) apresenta um verbo télico (morrer) numa situação em que se espera encontrar o presente perfeito com leitura existencial: a descrição de um evento que ocorreu no passado, mas tem efeitos no presente. Assim como esperávamos, nenhuma marcação específica com operadores de tempo ou advérbios é necessária. Por sua vez, a sentença em (22), com verbo atélico, exige operador de passado para a leitura existencial; sem ele, a leitura seria universal ou de presente simples, tal como se viu em (18), acima.

Finalmente, na seção anterior levantamos a hipótese de que as leituras de novidade e resultativa ocorreriam apenas com verbos télicos, sem marcação temporal explícita, mas podendo requisitar informações contextuais para serem especificadas. Os dados a seguir parecem confirmar nossa hipótese.

(23) CASA CHEGAR MENINO.

$$
\text { (JO, A.avi) }
$$

'O menino chegou em casa'

(24) $\mathrm{C}$
'O ratinho correu para o canto!'
(RE, I.avi)

Os exemplos (23) e (24) exemplificam o caso da leitura de novidade: ambas descrevem eventos que acabaram de acontecer, ou seja, cuja culminância está muito próxima do momento de fala. Em ambos os casos, conforme se previa, não há qualquer marcação explícita com operadores de tempo ou mesmo advérbios. De algum modo, esses exemplos também poderiam ter leitura resultativa, sendo adequados em contextos nos quais tanto a presença do menino em casa, como a permanência do rato no canto fossem relevantes.

QU

(25) MAMÃE ${ }_{1 \mathrm{~s}}$ PERGUNTAR ${ }^{++}$MOTO VER. (LE,H.avi)

'Perguntei, perguntei para mamãe, você viu a moto?'

(26) JOAO ENCONTRAR CHAVE JÁ (Contexto.avi)

'João já encontrou as chaves' 
As sentenças em (25) e (26) exemplificam casos de leitura resultativa, em si. No primeiro caso, nos interessa a utilização do verbo ver, na pergunta, já que, ali, o falante pergunta para a mãe se ela viu a moto com a intenção de saber onde está o veículo. Como se nota, não houve nenhuma marcação especial. Por outro lado, a sentença em (26) apresenta um operador/advérbio: já. Em verdade, essa sentença, tipicamente resultativa, foi construída em oposição a dois outros paradigmas: com suas correspondentes no passado, apresentadas em (27); e com $\mathrm{o}$ aspecto perfeito $(28) .{ }^{15}$

(27) a. J-O-A-O ENCONTRAR CHAVE ONTEM.

'João encontrou as chaves ontem'

(Contexto.avi)

b. ONTEM J-O-Ã-O ENCONTRAR CHAVE.

'João encontrou as chaves ontem.

(Contexto.avi)

(28) EU VAI AJUDAR JOÃO ELE ENCONTRAR CHAVE ANTES JÁ.

(Contexto.avi)

'Quando eu fui ajudar João, ele já tinha encontrado as chaves'

Ao contrário da leitura do presente perfeito, a de passado simples tem um operador temporal claro para marcar o TT, no caso de (27), o advérbio ontem. Por isso, aqui, a leitura não é de presente perfeito. Por sua vez, o aspecto perfeito, ao denotar a anterioridade de TSit em relação a TT, não pode ser equivalente ao passado simples, ao presente, ou mesmo ao presente perfeito. Vemos que em (28), o TT (quando eu fui ajudar o João) é posterior a TSit (João encontrar as chaves) e a presença do já aponta para essa anterioridade. Apesar disso, o uso de já em (26), com presente perfeito e (28), com o aspecto perfeito, parece indicar tanto a culminação anterior a TU, quanto o estado resultante em que o evento se encontra em TT.

Sendo assim, podemos concluir nossa análise indicando que, similarmente ao PB, a Libras apresenta as leituras de presente perfeito sem itens verbais específicos, ou seja, sem um auxiliar, como geralmente se observa em inglês ou espanhol. Entre os pontos de destaque, devemos considerar que o contexto exerce papel decisivo no tipo de leitura, porque afeta diretamente o momento de tópico. Tal afirmação corrobora as afirmações de Klein (1994; 2009), para quem toda sentença é pronunciada tomando como base um momento de tópico específico, expresso implícita ou explicitamente em um contexto.

Além disso, temos que levar em conta o importante papel das classes aspectuais, bem como o da composicionalidade na expressão dos diferentes tipos de aspecto e tempo verbal. Esses pontos ressaltam a importância de estudos translinguísticos sobre o modo de expressão temporal nas línguas naturais. Nossa descrição, portanto, vai ao encontro da afirmação de Rothstein (2008, p. 5), segundo a qual

${ }^{15} \mathrm{O}$ aspecto perfeito se caracteriza pela anterioridade de TSit em relação a TT, em casos como: Quando eu fui ajudar o João (TT), ele já tinha encontrado as chaves (TSit). 
different languages, and language families, make different choices as to what grammatical aspectual distinctions are expressed, and use different morphological or syntactic mechanisms to express them. Lexical aspectual distinctions are also expressed differently cross-linguistically, as is the telic/atelic distinction. If we assume some fundamental semantic distinctions, say between telic and atelic predicates, between basic Vendler event types, between perfective and imperfective viewpoints, then it is a challenge to investigate how and whether languages with different structural characteristics express these distinctions, and whether these distinctions are even grammatically relevant.

Com isso, Rothstein (2008) questiona se um conjunto pequeno de distinções (ou operações) semânticas relativas a tempo e aspecto é capaz de dar conta de vários sistemas aspectuais que se verificam nas diferentes línguas. ${ }^{16}$ Neste trabalho, a partir da proposta que assumimos, tais modos de expressão são poucos, previsíveis e bastante suficientes para descrever uma série de fenômenos, já que a expressão das noções tempo-aspectuais leva em conta diferentes fatores composicionais, sendo os principais deles, o aspecto lexical e o contexto.

\section{CONSIDERAÇÕES FINAIS}

Este trabalho teve como objetivo principal avaliar de que modo o tempo verbal conhecido como presente perfeito é expresso na Libras. Para tanto, assumiu com Klein (1994) a proposição de que tanto tempo quanto aspecto são categorias dêiticas cujas leituras são dadas pela relação entre intervalos de tempo: o momento de fala (TU), o momento de situação (Tsit) e o momento de tópico (TT). No que diz respeito à aspectualidade, considerou-se que as quatro classes de verbos (VENDLER 1957) e os valores aspectuais lexicais e gramaticais (operadores, por exemplo) são essenciais para expressar as relações de inclusão em intervalos de tempo, o que geraria diferentes leituras tempo-aspectuais, entre elas as do presente perfeito.

Escolhido o encaminhamento teórico para temporalidade e aspectualidade, o trabalho investigou as leituras do presente perfeito. Seguindo a caracterização de Laca (2010) para tais leituras, delimitou-se a análise dos dados de língua portuguesa e Libras para quatro tipos de leituras do presente perfeito: universal, existencial, novidade e resultativa. A investigação teve, então, a preocupação de responder as seguintes questões: como a Libras expressa as noções básicas de presente perfeito? Quais seriam as semelhanças e diferenças básicas de expressão do tempo verbal presente perfeito no PB e na Libras?

Para responder tais questionamentos, nosso percurso teórico ajudou-nos a levantar algumas hipóteses a fim de explicar como se dá a leitura de presente perfeito na Libras:

${ }^{16}$ Alguém poderia tomar a última parte da citação de Rothstein (2008) para argumentar que na Libras (e mesmo no PB) não seria relevante a distinção entre as leituras de presente perfeito e as leituras de presente ou passado. Embora aceitável, tal conclusão só é possível se assumirmos o desafio de comparar as características gramaticais entre os sistemas - algo que também Rothstein afirma. Daí a importância do presente trabalho. 
a) a leitura universal seria realizada com verbos atélicos e no tempo presente (default); no caso de repetição, deve-se inserir algum operador na sentença para indicá-la;

b) a leitura existencial poderia ser feita, de um lado, com verbos télicos, sem marcação temporal explícita (graças ao aspecto lexical do verbo), nem marcação de evento único obrigatórios, de outro, com verbo atélicos, mas, nesse caso, a marcação de passado seria obrigatória, já que seu aspecto lexical poderia levar a uma leitura de continuidade; e

c) as leituras de novidade e resultativa ocorreriam apenas com verbos télicos, sem marcação temporal explícita, mas podendo requisitar informações contextuais para serem especificadas.

Partindo de descrições já existentes para temporalidade e aspectualidade na Libras, como os trabalhos de Finau (2004, 2008) e Silva e Lessa-de-Oliveira (2016), foi possível demonstrar que essas três hipóteses se sustentam, o que é de grande valor para que se dê continuidade a esta pesquisa inicial, pois, para além do fato de o presente perfeito ser uma questão ainda não tratada pela linguística das línguas de sinais, a análise de enunciados da Libras e do PB apontou para similaridades na organização desse tempo entre as duas línguas. De acordo com os dados aqui investigados, ambas parecem se valer da composicionalidade, principalmente, entre tempo e aspecto lexical para denotar presente perfeito. Assim, o que promove a expressão dessa temporalidade nas duas línguas parece ser formas simples, sem, por exemplo, a necessidade de estruturas auxiliares, como em geral se observa em inglês ou espanhol: ${ }^{17}$

a) presente perfeito universal: requer eventos que permitem leitura atélica para expressar continuidade; e, para os casos de repetição do evento, operadores temporais ou advérbios auxiliam a denotar iteração;

b) presente perfeito existencial: realização simples de verbos télicos; quando o evento é atélico, a leitura é auxiliada pelo emprego de operador temporal ou expressões adverbiais; e

c) presente perfeito novidade e resultativa: emprego de verbos télicos; pode requisitar informações contextuais para ser especificado.

${ }^{17} \mathrm{Se}$, como se observa na literatura (veja-se Lopes, 2016), alguma dessas línguas puder expressar as leituras relacionadas ao presente perfeito em estruturas simples (sem auxiliares), fica ainda mais robusta a nossa pesquisa, no sentido de apontar para uma possível equivalência translinguística também estrutural. Agradecemos a um parecerista anônimo que, por suas considerações sobre o trabalho de Lopes (2016), permitiu que chegássemos a tais conclusões. 
Para concluir, precisamos afirmar que o presente trabalho contribui para a reflexão do papel fundamental do contexto, especialmente no recorte do momento de tópico (KLEIN 1994; 2009). Sem ele, uma mesma sentença poderia disparar leituras distintas; com ele, há uma especificação clara do TT, o que é fundamental para a expressão do tempo em língua natural. Além disso, o trabalho reforça a necessidade de uma pesquisa translinguística, especialmente no que diz respeito ao papel do aspecto lexical e de operadores gramaticais específicos para a expressão de tempo e aspecto em língua natural. Sem dúvida, a descrição aqui se mostra um ponto de partida importante para aprofundamento de outras leituras tempo-aspectuais em diversas línguas, sobretudo na Libras.

\section{AGRADECIMENTOS}

Agradecemos imensamente ao informante Surdo, que forneceu os dados específicos para esta pesquisa, à professora Lídia Silva (UFPR), à intérprete Carla, à audiência presente na Abralin 2017, em que discutimos pontos iniciais da pesquisa e aos pareceristas anônimos desta revista. Sem as contribuições de todos, este trabalho não seria possível.

\section{REFERENCIAS}

FELIPE, T. Relação sintático-semântica dos verbos e seus argumentos na LIBRAS. Tese (Doutorado) - Universidade Federal do Rio de Janeiro, Rio de Janeiro, 1998.

FERREIRA-BRITO, L.; LANGEVIN, R. Sistema Ferreira Brito-Langevin de Transcrição de Sinais. In: FERREIRA BRITO, L. Por uma gramática de Língua de Sinais. Rio de Janeiro: Tempo Brasileiro, 1995.

FINAU, R A. Os sinais de tempo e aspecto na Libras. 233 f. Tese (Doutorado em Letras) - Universidade Federal do Paraná, Curitiba, 2004.

FINAU, R A. As marcas linguísticas para as categorias e aspecto na Libras. In: QUADROS, Ronice M. de. (Org.). Estudos Surdos III. Petrópolis: Arara Azul, 2008, pp. 260-300.

ILARI, R. Notas sobre o passado composto em português. Revista Letras, Curitiba, n. 55, pp. 129-152, jan./jun. 2001. Editora da UFPR.

KLEIN, W. Time in language. London: Routledge, 1994.

KLEIN, W. How time is encoded. In: KLEIN, W.; LI, P. (eds.). The expression of time. Berlin: Mouton de Gruyter, pp. 39-82, 2009.

LACA, B. Perfect Semantics: How Universal Are Ibero-American Present Perfects? In: BORGONOVO, C. et al. (eds.). Selected Proceedings of the 12th Hispanic Linguistics Symposium. Somerville, MA: Cascadilla Proceedings Project, 2010, p. 1-16. Disponível em: <http://www.lingref.com/ cpresente perfeito/hls/12/paper2401.pdf> Acesso em: 20 dez. 2016.

LEVINSON, S. C. Presumptive meanings: the theory of generalized conversational implicature. Massachusetts Institute of Technology: A Bradford Book, 2000. 
LOPES, T. L. A realização morfológica do aspecto perfect no português do Brasil e no inglês da Inglaterra - uma análise comparativa. Rio de Janeiro: Programa de Pós-Graduação em Linguística/ Faculdade de Letras. Universidade Federal do Rio de Janeiro. Dissertação de Mestrado, 2016.

MEDEIROS, A. B. de. O pretérito perfeito composto e sua interpretação. Revista Linguística, v. 6 (1), pp. 86-102, 2010.

MITTWOCH, A. The English Resultative perfect and its relationship to the Experiential perfect and the simple past tense. Linguistics and Philosophy, 31, 2008, pp. 323-351.

MOLSING, K. Universal and Existential Perfects in Brazilian Portuguese. Revista Letras (Curitiba), n. 73, pp. 131-150, set./dez. 2007. Editora da UFPR.

PORTNER, P. The (temporal) semantics and (modal) pragmatics of the perfect. Linguistics and Philosophy 26: 459-510, 2003.

REICHENBACH, H. Elements of symbolic logic. New York: The MacMillan Co, 1947.

ROTHSTEIN, S. Structuring Events. Oxford: Blackwell, 2004.

ROTHSTEIN, S. (ed.) Theoretical and crosslinguistic approaches to the semantics of aspect. Amsterdam: John Benjamins, 2008.

SCHMITT, C. Cross-linguistic variation and the Present Perfect: the case of Portuguese. ZAS Papers in Linguistics 16, 2000, pp. 68-99.

SILVA, I. B. de O.; LESSA-DE-OLIVEIRA, A. S. C. Propriedades funcionais verbais na língua brasileira de sinais. Revista Linguística (UFRJ), v. 12, n. 2 (2016).

SMITH, C. The parameter of Aspect. 2. ed. Dordrecht: Kluwer Academic Publishers, 1997.

VENDLER, Z. Verbs and times. Philosophical Review 56, pp.143-160, 1957.

WACHOWICZ, T. C. O aspecto do auxiliar. Revista de Estudos da Linguagem (Belo Horizonte), v. 14, n.2, pp. 55-75, jul./dez, 2006.

WACHOWICZ, T. C. Telicidade e classes aspectuais. Revista do Gel, v.5, n.1, p.57-68, 2008.

WACHOWICZ, T. C.; FOLTRAN, M. J. Sobre a noção de aspecto. Cadernos de Estudos Lingüisticos, Campinas, v. 48, pp. 211-232, 2006. 